\title{
Cases requiring care for tracheal perforation during intubation: larynx Ca patients who underwent radiotherapy
}

\begin{abstract}
Radiotherapy has been used in the treatment of larynx carcinoma. In patients with headneck cancers administered radiotherapy have two important problems regarding airway management. First problem is securing airway with direct laryngoscopy is usually difficult due to the movement restriction develops in the neck exposed to radiation due to widespread fibrosis and adhesions. The other problem is in addition to fibrosis is tissue necrosis. We would like to present this case report to highlight the importance of predicting the risk of tracheal perforation due to radionecrosis during intubation procedure in larynx ca patients administered radiotherapy and of taking care during the procedure.
\end{abstract}

Keywords: larynx carcinoma, radiotherapy, tracheal perforation
Volume 2 Issue 4 - 2015

\author{
Ozkan Onal,' Emine Aslanlar,' Cagdas \\ Elsurer, ${ }^{2}$ Aysun Ozdemirkan,' Jale Bengi \\ Celik' \\ 'Department of Anesthesia and Intensive Care, Selcuk \\ University, Turkey \\ ${ }^{2}$ Department of Otorhinolaryngology, Selcuk University, Turkey
}

Correspondence: Ozkan Onal, Department of Anesthesia and Intensive Care, Selcuk University, Konya, Turkey, Tel +905059052252, Email drozkanonal@selcuk.edu.tr

Received: March 30, 2015 | Published: May 12, 2015

\section{Introduction}

Radiotherapy has been used for over 70 years in the treatment of larynx carcinoma. ${ }^{1}$ In head-neck cancers, following radiotherapy, movement restriction develops in the neck exposed to radiation due to widespread fibrosis and adhesions. In these patients, securing airway with direct laryngoscopy is usually difficult. ${ }^{2}$ Therefore, in difficult laryngoscopy, the probability of harming airway with manipulations increases. In patients administered radiotherapy, another problem in addition to fibrosis is tissue necrosis. ${ }^{3-8}$ As the likelihood of harming airway increases in difficult laryngoscopy, care should be taken for perforation in patients administered radiotherapy considering the probability of tissue necrosis.

\section{Case}

1 year ago, a 52year old male patient was diagnosed T3 glottic cancer and he did not consent to operation and he was underwent radiotherapy of the neck region due to lymph node metastasis (Figure 1). About four months after radiotherapy, halithosis and difficulty in breathing occurred and ear nose throat department planned tracheostomy (Figure 2). Patient had cachectic appearance and anaerobic odor was present. Preoperative $\mathrm{SpO}_{2}: 82 \%$, blood presure: $140 / 80 \mathrm{~mm} / \mathrm{Hg}$ and heart rate: 110 beats/min. In anesthesia induction, $2 \mathrm{mg} / \mathrm{kg}$ propofol, $0.6 \mathrm{mg} / \mathrm{kg}$ rocuronium (Esmeron, Schering Plough, Turkey) and $1.5 \mathrm{mcg} / \mathrm{kg}$ fentanyl (Talinat, Vem, Turkey) were administered. After oxygen saturation value was increased from $82 \%$ to $98 \%$ with mask ventilation, suspension blade was placed. In endoscopy, it was observed that right side of trachea was necrotic in subglottic region and necrosis extended towards strap muscles (Figure 3). While necrotic areas are cleaned, desaturation was prevented by $100 \% \mathrm{O}_{2} 18 \mathrm{lt} / \mathrm{min}$. flow insufflations. During skin incision for tracheostomy, intubation was made carefully with endoscopy. At the level of $2^{\text {nd }}$ and $3^{\text {rd }}$ rings of trachea, necrotic areas at right lateral were excised and cannula was placed. In the meantime biopsy was taken and tumor didn't occur in the biopsy result. Patient was awakened without any complications and transferred to clinic.

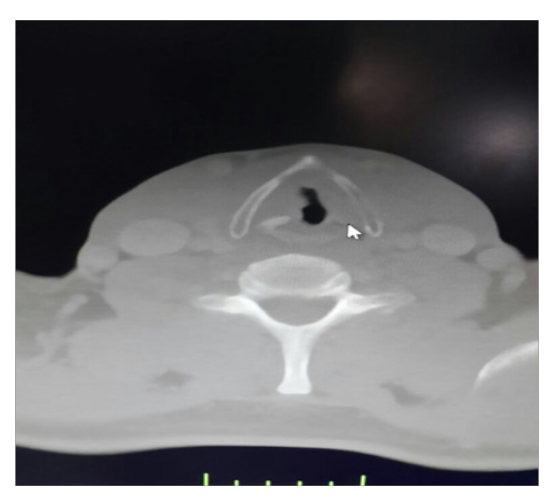

Figure I CT scan shows left vocal cord tumour.

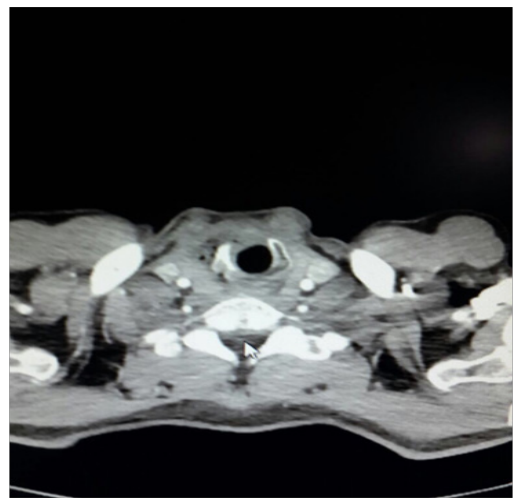

Figure 2 CT scan shows no subglottic extantion.

\section{Discussion}

In patients diagnosed with head-neck cancer, anesthesia approach and airway management requires caution. In time, airway may change in patients. In patient in whom securing airway is very easy prior to resection surgery, subsequent to surgery or radiotherapy even 
mask ventilation may become impossible, because during surgical intervention, anatomic mark points are also resected. Moreover, fibrosis developing postoperatively or after radiotherapy restricts the mobility of the airway. Therefore, intubation with direct laryngoscopy may be difficult and excretion of excessive force may harm intact airway. Radiotherapy has long been used in the therapy of larynx carcinoma. One of the well known complications of this method, used in the treatment of head and neck neoplasms, is radio necrosis. It is possible to encounter tissue necrosis involving soft tissues, joints and bones. ${ }^{3-8}$ Chondroradionecrosis is one of the rare and late complications of radiotherapy of larynx cancers and may arise in a large time period ranging between 1 to 50years. ${ }^{1}$ Two cases reported in the literature as delayed complications, occurred 44 and 50 years later respectively while in the present case this period was four months.

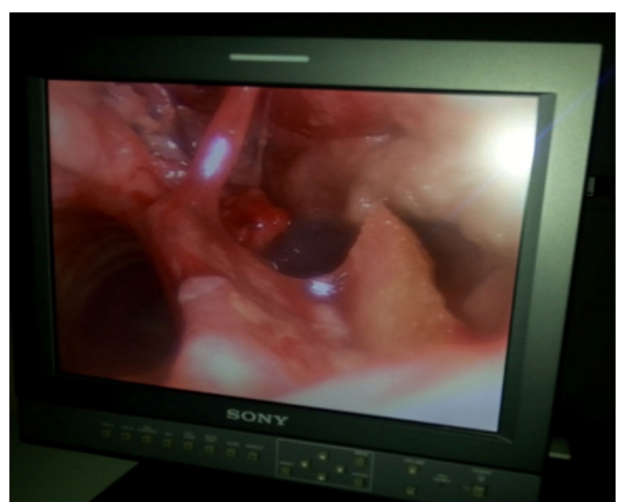

Figure 3 Image of the tracheal perforation due to the radionecrosis.

Chondroradionecrosis leads to risks for the patients such as acute respiratory distress, deep neck infection, and septicemia. In addition, there is also risk of rupture associated with necrosis due to manipulations and to intracranial pressure.

In the present patient, rupture developed owing to Chondroradionecrosis. As necrotic areas were noticed during endoscopy, care was taken during intubation and cuff pressure was kept very low.

In conclusion, during endoscopic examination of patients who have undergone radiotherapy, cautions should be taken for necrotic areas and during intubation, soft intubation should be tried in order to prevent possible rupture. If the presence of necrotic areas is suspected, awake fiber optic intubation should be carried out instead of direct laryngoscopy.

\section{Conclusion}

In patients with larynx ca, while it is easy to predict difficult airway due to fibrosis caused by radiotherapy, it is more difficult to predict tracheal perforation associated with necrosis, which is a late complication. Hence, even if a patient with head neck cancer has been administered anesthesia many times previously, during each surgical intervention, airway should be evaluated carefully and chondronecrosis and tracheal perforation should always be kept in mind.

\section{Acknowledgments}

None.

\section{Conflicts of interest}

The authors declare that there are no conflicts of interest

\section{Funding details}

None.

\section{References}

1. Fitzgerald PJ, Koch RJ. Delayed radionecrosis of the larynx. Am J Otolaryngol. 1999;20(4):245-249.

2. Alkiş N, Duru FB. Anesthesia in head-neck cancer. $K B B$ ve $B B C$ Dergisi. 2003;11(2):81-91.

3. Barton J, Slevin NJ, Gleave EN. Radiotherapy for pleomorphic adenoma of the parotid gland. Int J Radiat Oncol Biol Phys. 1992;22(5):925-928.

4. Birzgalis AR, Ramsden RT, Farrington WT, et al. Severe radionecrosis of the temporal bone. J Laryngol Otol. 1993;107(3):183-187.

5. Bras J, De Jonge HK, Van Merkesteyn JP. Osteoradionecrosis of the mandible: pathogenesis. Am J Otolaryngol. 1990;11(4):244-250.

6. Kocatürk S, Kurukahvecioğlu S, İncesulu A, et al. A case of laryngeal chondroradionecrosis. Kulak Burun Bogaz İhtis Derg. 2003;11(1):29-32.

7. Lozza L, Cerrota A, Gardani G, et al. Analysis of risk factors for mandibular bone radionecrosis after exclusive low dose-rate brachytherapy for oral cancer. Radiother Oncol. 1997;44(2):143-147.

8. Zimman OA. Reconstruction of the neck with two rotation advancement platysma myocutaneous flaps. Plast Reconstr Surg. 1999;103(6):1712-1714 